\title{
El Manifiesto Liminar y su vigencia en la realidad latinoamericana
}

\author{
María Galindo ${ }^{1}$ \\ Universidad Pedagógica Experimental Libertador, Venezuela \\ mariagalindo2008@hotmail.com
}

\begin{abstract}
Resumen
El presente artículo de investigación tiene como objetivo analizar el discurso contenido en el Manifiesto Liminar y su vigencia con la actual realidad de la educación universitaria en Latinoamerica. Para ello se ha dispuesto estudiar en primera instancia el contexto socio político en el cual ocurre la Reforma Universitaria de 1918, seguidamente se indagan situaciones en la región que llegan a evidenciar la vigencia del Manifiesto. Se analizan documentos y eventos relacionados a la Reforma. Se concluye que aun el Manifiesto Liminar se encuentra vigente en nuestra región ya que es posible ubicar elementos que demuestran el deterioro del sistegma de educación superior. Se cree en que la Universidad Latinoamérica puede transformarse desde la voluntad política y la participación activa de los jóvenes en su sistema de formación académica que estimule el desarrollo de la ciencia y la tecnología.
\end{abstract}

Palabras clave: Manifiesto Liminar, Universidad, Latinoamérica.

\section{Liminar Manifesto and its validity in the Latin American reality}

\begin{abstract}
This research article intends to analyze the speech included in the Liminar Manifesto and its effectiveness with the current reality of university education in Latin America. For this purpose, it has been arranged to study, as a first instance, the socio-political context in which the University Reform of 1918 occurs, subsequently it is looking at the situations in the region that evidences the Manifesto's validity. It is analyzed documents and events linked to the Reform. It is conduced that the Liminar Manifesto is still effective in our region because it is possible to find items that prove the decline in higher education system. It is thought that Latin American University can transform itself from political willingness and the active participation of young people in their academic training system that promotes the development of science and technology.
\end{abstract}

Key words: Liminar Manifesto, University, Latin America.

1 Cursa el Doctorado Latinoamericano en Educación, Políticas Públicas y Profesión Docente en la Universidad Pedagógica Experimental Libertador - Instituto Pedagógico de Miranda (Venezuela). Este artículo llega a la revista ENTORNOS en esos diálogos que solo puede abrir internet y con la necesidad de unir más voces a la ardua lucha que se hace desde las universidades. 


\section{Introducción}

Leer el discurso contenido en el documento Manifiesto Liminar de la Reforma Universitaria de 1918, próximo a cumplir los 100 años, y encontrar similitudes con la actual realidad universitaria latinoamericana es un asunto de cuidado e importancia que debería causar gran preocupación, pues es un documento escrito hace casi un siglo aproximadamente. Este Manifiesto ocurre en un contexto socio-políticohistórico que a la fecha debería estar superado dentro de la estructura universitaria.

Este artículo se encarga precisamente de examinar el contexto histórico, político y social de la época en la cual acontece el Manifiesto Liminar y poder analizarlo a la luz de los acontecimientos actuales. Realmente, es el momento para que todos los ciudadanos de un país examinen su conciencia y su realidad: ¿Tenemos una Universidad promotora $y$ productora de conocimiento y desarrollo o más bien Latinoamérica aún conserva una estructura universitaria signada por la involución?

\section{El Manifiesto Liminar: su origen y contexto}

Para analizar el Manifiesto Liminar, su contenido y su relación con la actual realidad, es fundamental saber cómo se llegó a este escrito que impacto a la sociedad latinoamericana. El Manifiesto Liminar es básicamente un documento público impulsado por los estudiantes de la Universidad de Córdoba que integró a los estudiantes latinoamericanos en razón de la lucha contra un sistema universitario signado por la imposición del poder aristocrático y eclesiástico de la época, fíjense en este pasaje que delata lo anterior

Las universidades han sido hasta aquí el refugio secular de los mediocres, la renta de los ignorantes, la hospitalización segura de los inválidos y -lo que es peor aún- el lugar en donde todas las formas de tiranizar y de insensibilizar hallaron la cátedra que las dictara. Las universidades han llegado a ser así el fiel reflejo de estas sociedades decadentes que se empeñan en ofrecer el triste espectáculo de una inmovilidad senil. (Manifiesto Liminar, 1918)

Para el 1918, año en que Deodoro Roca, representante de la Federación Universitaria de Córdoba redacta el Manifiesto Liminar la Universidad argentina estaba en crisis principalmente de carácter ideológico, de imposición de estructuras autoritarias que solo buscaban el poder para apropiarse del claustro académico. El propio documento señala "acabamos de romper la última cadena que en pleno siglo XX nos ataba a la antigua dominación monárquica y monástica".

El Manifiesto Liminar es precisamente una reforma universitaria que los jóvenes argentinos de la época plantearon basándose en los alcances de la universidad a principios del siglo XX, una universidad caracterizada por la carencia de ese pensamiento crítico, analítico e independiente, elementos que son propios de un sistema universitario que impulse el desarrollo de un país, sin embargo lo que predominaba era una universidad promotora del conformismo y el atraso.

En este sentido, es así cómo se describe el contexto político social de la época: "La rebeldía estalla ahora en Córdoba y es violenta, porque aquí los tiranos se habían ensoberbecido y porque era necesario borrar para siempre el recuerdo de los contra-revolucionarios de Mayo" (Manifiesto Liminar, 1918). Este pasaje delata que el clima político-social de Córdoba estaba signado por la violencia y la lucha ideológica, los denominados "contra - revolucionarios de Mayo" estaban identificados como aquellos que representaban ideales contrarios al suceso histórico libertario acontecido en el año 1810 en argentina denominado la Revolución de $\mathrm{Mayo}^{2}$.

2 “la Revolución de Mayo la constituyó una serie de acontecimiento histórico ocurrido en el año 1810 en la ciudad de Buenos Aires el cual desemboco posteriormente en la independencia de Argentina del imperio español".(Telesur, 2017) 
Esta situación nos indica que el contexto que caracterizaba a la Argentina en los previos de la gestación del Manifiesto Liminar era un clima donde los jóvenes se sentían dominados nuevamente por una tiranía que oprimía su libertad en todo sentido y la Universidad lo reflejaba, vale la pena reflexionar entonces ¿Puede una universidad sumergida en la tiranía producir verdadera ciencia? ¿Acaso la ciencia, el hacer científico no requiere libertad? Al respecto el diccionario electrónico (2018) señala que

La Ciencia (en latín scientia, de scire, que significa "conocer"), es el conjunto de conocimientos sistemáticos sobre la naturaleza, los seres que la componen, los fenómenos que ocurren en ella y las leyes que rigen estos fenómenos. La ciencia es una facultad del hombre que le permite encontrar explicaciones a los fenómenos estudiados y respuestas a las interrogantes planteadas sobre acontecimientos determinados, mediante un conjunto de ideas que pueden ser provisionales, pues con la actividad de búsqueda continua y el esfuerzo de hombres y mujeres, estas explicaciones pueden variar y constituir un nuevo conocimiento.

Desde este ámbito debe comprenderse que el hacer científico en el ámbito universitario es como el oxigeno para el cuerpo, vital para su existencia. Desdeesta perspectiva, vale la pena preguntarse: $¿ \mathrm{Si}$ una universidad no aporta conocimiento científico qué justifica su existencia? Esa Universidad de atraso y sub-desarrollo era la Universidad a la cual los jóvenes de Córdoba se oponían. El Manifiesto es un documento que se distingue incluso por su carácter visionario pues nos indica el destino de las Universidades secuestradas por la tiranía y la opresión: "Dentro de semejante régimen, Ias fuerzas naturales Ilevan a mediocrizar Ia enseñanza" (Manifiesto Liminar, 1918). Lo citado hace evidente el objetivo de quienes tenían el poder, su propósito no era otro que neutralizar la verdadera ciencia y mantener así el dominio de la población. Desde estas consideraciones, hay que tener presente que la Educación, en particular, guarda como principal fin formar ciudadanos y hombres libres, críticos, productores de ciencia y tecnología, es por ello que cualquier proyecto tiránico, buscará oprimir y dominar la educación para poder alcanzar sus fines de dominio de una población.
En el contexto, el Manifiesto Liminar luchaba contra el objetivo de dominar a la población, pues los que tenían el poder reconocían el "poder" contenido en la educación universitaria para el dominio de sus ciudadanos. Dentro de esta realidad a ningún sistema de gobierno autócrata, monárquico, totalitario, dictatorial, entre otros; que limite la libertad, la crítica, el pensamiento le conviene tener un sistema educativo contrario a sus ideales de dominación. Una Universidad hacedora de ciencia que inspire y motive al desarrollo de sus jóvenes universitarios y del país en si será imposible de coexistir con una estructura de gobierno no democrática y esta situación delata el afloramiento del conflicto político - social entre la juventud de Córdoba y quienes ostentaban el poder de la Universidad en ese entonces.

Los sistemas de gobierno oprimentes por su naturaleza buscan apoderarse de la educación pues tener el control de la educación universitaria y de la educación en sí; permite a los representantes o dirigentes de estos movimientos políticos autoritarios tener el control de la conducta de los ciudadanos. La "inmovilidad senil" tal como lo señalará el Manifiesto representa adormecer a la población, callar su crítica, su pensamiento, su capacidad de transformar, de producir conocimiento, en otras palabras, controlar la educación desde esta perspectiva es mutilar el ser humano, esta situación es el fundamento de la lucha emprendida por los jóvenes argentinos en el año 1918. Es importante destacar que aunque este movimiento se gesto en Córdoba pudo abarcar a los jóvenes de Latinoamérica por presentar realidades comunes.

Este Manifiesto, nos insta a la necesidad de tomar en cuenta las transformaciones políticas, económicas, sociales y educativas que debe experimentar una nación, solo así es posible hablar de una verdadera Reforma Universitaria. El Manifiesto Liminar evoca un sentimiento de libertad de la juventud latinoamericana indignada con tanta mediocridad en sus universidades dado que la ignorancia y la tiranía era lo que caracterizaba al claustro académico. La Universidad era utilizada tan sólo para abusar 
del poder, y no para su verdadero fin, producir conocimiento y dar al país profesionales e investigadores promotores de su desarrollo científico y tecnológico.

La Universidad Argentina para ese entonces era el fiel reflejo de la sociedad la cual estaba oprimida, sin libertad, sin pensamiento propio, pasividad extrema, en fin, sin el más mínimo indicador de un posible desarrollo para ese nuevo siglo, del cual solo habían transcurrido 18 años. En este sentido, es válido reflexionar que no puede haber ciencia donde no hay sentido crítico. Para aquel entonces la Universidad se había convertido en un brazo ejecutor de la tiranía y el abuso del poder. Lo que importaba realmente era formar al hombre para obedecer pasivamente pero esos jóvenes de Argentina, despertaron y elevaron su voz de protesta, cansados de la ausencia del verdadero quehacer universitario, cansados de la pseudociencia, cansados de régimen que violaba sus libertades y derechos.

El Manifiesto Liminar hace una declaración muy concreta "Nuestro régimen universitario aun el más reciente- es anacrónico", De acuerdo al diccionario electrónico (2018) “El adjetivo anacrónico se utiliza para calificar a aquello que tiene anacronismo: es decir, que resulta incongruente respecto a la época en la cual se presenta. Se trata de elementos que, por su condición o sus características, son propios de un tiempo diferente".

Esto evidencia como un grupo de personas aferradas a las prebendas del poder habían convertido a la universidad en un claustro sin identidad, pues para la estructura de la época era vista negativamente y no se correspondía a lo que en términos estrictos una universidad debe aportar al sistema-país. Más bien era una universidad signada por la involución a pesar de apenas estar entrando a un siglo que prometía mucho. Definitivamente la Universidad conservaba un régimen del pasado, un atraso de más de un siglo y que para la fecha debía estar superado, por ello se le denomino "anacrónico".

En esencia el Manifiesto Liminar representa la lucha estudiantil por tener una genuina
Universidad, una donde se forma para el desarrollo del pensamiento, de la ciencia y la tecnología, que busca formar ciudadanos critico y libres, no sumisos a ningún tipo de sistema autoritario. Definitivamente el Manifiesto Liminar abrió la puerta a la reforma universitaria en Latinoamérica, a la lucha por una Universidad hacedora de ciencia, una universidad moderna y democrática ante todo.

\section{Vigencia del manifiesto liminar. Transformación requerida}

Hace 100 años los jóvenes estudiantes de Córdoba armaron un movimiento estudiantil para oponerse a la tiranía y a la imposición, de allí surge lo Reforma Universitaria que quedó plasmada en el Manifiesto Liminar. Ahora bien hasta qué punto la Universidad Latinoamericana ha superado el contexto donde surge el Manifiesto.

¿La Universidad Latinoamericana se ha hecho consiente de su poder para generar libertad?, Es oportuno reconocer que la libertad comienza desde nuestro pensamiento, y la universidad debe ser promotora de un pensamiento libre y crítico, transformador, creativo y científico. Esta realidad nos lleva preguntarnos qué ha pasado con la universidad Latinoamérica que aún sigue sumergida en el sub-desarrollo, nada alentador. La realidad muestra que las Universidades que siguen dominando la escena mundial son las Universidades provenientes de potencias mundiales, lo certifica el Ranking Académico Mundial de las 500 mejores universidades del mundo (2015) donde apenas la Universidad de Buenos Aires se ubica entre el puesto 151-200, la Universidad Federal de Rio de Janeiro se ubica entre 301-400, Universidad Minas de Gerais entre 401-500; estos resultados demuestran un gran vacío del sector Universitario Latinoamericano.

Pero el vacío que se describe, es parte de tener universidades con presupuestos mediocres, profesores mal pagados, ausencia de una cultura investigativa institucionalizada que este más allá de esfuerzos politizados carentes de ningún control de calidad educativa y que tanto daño le hacen a la educación, tal es el caso particular 
de Venezuela, donde encontramos varios modelos universitarios, uno constituido en las Universidades Autónomas, las Universidades Experimentales y por otro lado, el proyecto universitario que forman parte de la Misión Sucre, un modelo poco difundido que aun carece de una estructura consolidada de formación con calidad en términos científicos. Las Universidades venezolanas han entrado una etapa de deterioro de sus servicios. Se ve con tristeza como muchos profesores universitarios dejan sus cargos y abandonan su carrera de formación científica por los pocos beneficios que esta ofrece para atender sus necesidades primarias. Particularmente, las Universidades venezolanas se están quedando sin su mejor recurso, profesionales altamente capacitados que deciden a emigrar a otras tierras en búsqueda de una mejor calidad de vida. Esta situación que pareciera no importar es grave, estamos quedando sin talento humano capacitado para promover el desarrollo en el país.

Latinoamérica necesita invertir en la educación universitaria sin reservas, pero la realidad es todo lo contrario, las grandes diferencias entre las naciones comienzan con la inversión en investigación, según datos del Banco Mundial países como Alemania destinó para el año 2015 el 2,88\% del Producto Interno Bruto (PIB) para gasto en Investigación y Desarrollo; Estados Unidos para el mismo año destinó 2,79\% de PIB; Finlandia destinó $2,90 \%$ en gasto de investigación y desarrollo; mientras que países como Nicaragua sólo destinaron el $0,11 \%$ de su PIB, Perú 0,12\%, México 0,55\%, Chile 0,38\%.

Desde esta realidad la revisión/reflexión de los países (del mal denominado) tercer mundo debería apuntar a: ¿Cómo obtener desarrollo si no se invierte en investigación y desarrollo? La inversión más rentable y duradera para que un país pueda mantener niveles acordes de desarrollo, está inmersa en la educación de sus ciudadanos y esta debe tener por presupuestos dignos que permitan mantener una estructura universitaria de calidad, donde sea posible tener servicios dignos, profesores bien pagados, sistema de investigación y formación de investigadores, etc.
Desde igual perspectiva, el Manifiesto contiene un interesante segmento donde reivindica el verdadero rol del profesor que asume la responsabilidad de dirigir nuestras universidades "La autoridad, en un hogar de estudiantes, no se ejercita mandando, sino sugiriendo y amando: enseñando", significa esto que el poder no es para oprimir ni imponer, el poder es para gestionar y liderizar los procesos de formación de nuestros estudiantes dentro de parámetros de respeto, eficacia y eficiencia de todo el proceso educativo. Hace falta sentirse identificado con el arte de enseñar, pues el acto más noble de la profesión docente es formar ciudadanos aptos para la vida y el desarrollo de nuestros países.

Desde la esfera universitaria no se trata de enfocar los docentes del nivel como los olimpos del conocimiento, capaces de tener seudopoder sobre el pensamiento de sus estudiantes y ser poseedores de la verdad absoluta, pues es un gravísimo error que condena a nuestras universidades a la involución y por ende, a nuestros países. Al docente universitario le corresponde asumir el rol de liderar los cambios y transformación que clama nuestra América.

Es indispensable superar la universidad del 1918, ¿Será que hace falta otro Manifiesto Liminar? En Latinoamérica no podemos volver a estructuras dominantes del poder, necesitamos una región donde predomine una verdadera democracia, una verdadera libertad que no limite el pensamiento y menos la libertad de expresión.

En el Manifiesto Liminar, su discurso político y social, engloba lo que podríamos denominar un diagnostico muy certero de la realidad universitaria de la época. Este documento proporciona el elemento necesario para planificar nuestro avance y progreso como región pues es un sentido diagnóstico de la realidad de la estructura universitaria. Ese discurso nos proporcionó la posibilidad de identificar los males que afectaban nuestra universidad y también nos daba la oportunidad de examinar las posibles respuestas a muchas de las situaciones que acontecían en el claustro universitario pero ¿Qué ocurrió en el camino 
que no se han podido superar muchos de estos males? ¿Por qué tanto deterioro de nuestras universidades?, ¿Por qué nuestros gobernantes les cuesta tanto invertir en educación, desarrollo e investigación?, en fin hace falta examinar el estado actual de nuestra educación superior latinoamericana y en definitiva, asumir que la juventud de América merece una educación con dignidad y libertad pues es la garantía del desarrollo de nuestra región.

"Los dolores que nos quedan son las libertades que nos faltan" (Manifiesto Liminar, 1918). Tal comolo señala el documento en estudio, a la universidad Latinoamérica a pesar de haber transcurrido 100 años de aquella Reforma Universitaria le hace falta recuperar libertad que comienza por construir políticas publicas de Estado coherentes que permitan hacer de la Educación Superior un servicio de calidad; y la calidad en este contexto significa fomentar su desarrollo, supone esto un esfuerzo continuo y sostenido de los actores políticos que juegan un papel fundamentar en el desarrollo de un país. No hacerlo, implica su atraso. A la Universidad Latinoamérica le hace falta evolucionar, Sebastián (2007) afirma:

Las relaciones entre conocimiento científico y tecnológico y gobernabilidad están implícitas en los países más desarrollados como consecuencia de la asimilación e interiorización de la ciencia y la tecnología en las dinámicas sociales y económicas... En los países de menor desarrollo existe un problema de reconocimiento práctico de las relaciones entre la ciencia-tecnología y la gobernabilidad. Se constata una contradicción evidente entre el discurso político, en el que suele haber un reconocimiento del papel estratégico del conocimiento y la práctica de las políticas públicas, que raramente priorizan suficientemente el desarrollo científico y tecnológico y el fomento de la innovación. (p. 198)

La realidad demuestraqueaunquesereconozca la importancia del papel del conocimiento en nuestro desarrollo, hace falta un mayor empuje hacia la práctica de la ciencia, la innovación, la tecnología a través de la producción científica del conocimiento, para lo cual se requiere priorizar inversión en sectores como el educativo, eje base del desarrollo de una nación. Las Universidades tienen la responsabilidad de ser líderes en producción de conocimiento parar nutrir el anhelado desarrollo, pero necesitamos universidades libres y con presupuestos dignos tal como se señalo en párrafos precedentes. Ya el Manifiesto Liminar lo exaltaba, pero al parecer no ha sido superada esta realidad.

Particularmente, lasnaciones latinoamericanas tienen que dejar de ser simples receptoras de tecnologías para convertirse en productoras de las mismas a través de los avances en la producción del conocimiento. Hace falta reconsiderar el rol del docente como un simple depositario de información en sus estudiantes y evolucionar a la figura de un docenteinvestigador, considerado un actor capaz de producir conocimiento científico.

Hoy los países desarrollados tienen una gran posición a nivel científico y tecnológico, pues han llevado a la práctica políticas públicas que demuestran que invertir en investigación es algo rentable y necesario para su progreso, pero pareciera ser que la investigación se piensa solo desde y para los países desarrollados, al respecto Elizondo y Ayala (2007) señalan:

La escasa demanda de conocimientos endógenamente generados ha caracterizado al sector productivo latinoamericano. Esta es una de las debilidades más fuertes del proceso de desarrollo de Latinoamérica, la falta de producción científica y la poca relación entre el conocimiento producido y el sistema económico, y en las consecuencias de ello para la investigación y la enseñanza superior en el continente (p.5).

Lo citado pone en evidencia que nuestro sistema universitario está en desventaja frente a otras realidades que han decidido proyectar su progreso desde la generación de conocimiento. La sociedad se globalizó, el mundo ya es global pero a nosotros nos falta desarrollo en estas dimensiones, y el Manifiesto Liminar lo advirtió (y lo sigue diciendo un siglo después), tenemos que abandonar prácticas no democráticas del poder, debemos invertir en investigación para producir conocimiento, la figura del profesor 
universitario debe deslindarse de la práctica del exclusivo dador de clases (peón del sistema, reproductor del discurso del status quo), es necesario que esa figura de docente emigre, evolucione a una formación y figura del docenteinvestigador. No podemos seguir manteniendo esquemas fijos cuando la educación es un proceso tan dinámico.

Dentro de estas consideraciones, una de las problemáticas que enfrentan las políticas públicas educativas en la región latinoamericana es el cómo mejorar el desempeño de sus docentes $^{3}$. En tal sentido, desde el análisis de lo dicho en el Manifiesto Liminar la formación de docentes-investigadores debe ser parte de la cultura investigativa entendida en términos de Barreto (2006), quien la define como:

[La] institucionalización de la investigación en un país y en las organizaciones einstituciones que lo conforman, lo cual se traduce en que los actores de uno adoptan ésta como un estilo de vida, de acción. En consecuencia, el ser, el hacer y el convivir está orientado por la actitud de investigación asumida por dichos actores para abordar las situaciones-problemas que se presentan. (p. 123)

Lo citado expone claramente la necesidad de plantear políticas públicas que permitan institucionalizar la formación de docentesinvestigadores, para lo cual hace falta esa estructura de planificación, financiamiento, dotación, infraestructura, planes y programas de formación deinvestigadores; que permitan sentar las bases del desarrollo del acto investigativo por parte de los docentes al respecto Sebastián (2007) señala:

La cultura científica proporciona a las personas una mejor comprensión de sí mismas, de la naturaleza, de la sociedad y del sistema científico-técnico. Propicia la modernización y el papel activo de la sociedad, en la medida en que aumenta la capacidad de asimilación del cambio, la superación de una posición de simple receptor pasivo de la tecnología, el aprovechamiento de las oportunidades derivadas de los nuevos conocimientos y la posición crítica y responsable frente a los riesgos y dilemas derivados de los mismos ( $p$. 200)

Según lo expuesto, la cultura científica debe formar parte de una sociedad que aspire a su desarrollo. La región latinoamericana debe superar la posición pasiva de ser receptora de tecnología para ser productora de conocimiento. Indiscutiblemente hace falta acudir espacios y oportunidades de desarrollo, la educación es uno de ellos, la sociedad reclama un docente crítico, creativo, innovador, que rompa la barrera de lo tradicional, que produzca, ese docente es el docente-investigador.

Desde esta perspectiva, en los países latinoamericanos existe una profunda necesidad de apuntalar al desarrollo de la formación docente pues esta se vislumbra como uno de los desafíos más críticos que debe enfrentar la sociedad latinoamericana, pues los nuevos conocimientos tienen su origen en la investigación científica y este debe ser liderado por docentes-investigadores del sector universitario los cuales representan actores claves para producir conocimiento y desarrollo desde su ser, hacer y saber educativo. Es por esto que el Manifiesto Liminar es una lucha, una consigna que aún guarda absoluta vigencia con la realidad que viven nuestras naciones latinoamericanas y marca la ruta para batallas que aún no se han librado en muchas de nuestras naciones latinoamericanas.

\section{Conclusión}

El Manifiesto Liminar es un documento que cuestiona la concentración del poder en la universidad, el estudiantado argentino saca del claustro el errado concepto de autoridad, $\mathrm{y}$ destruye las falsas reformas universitarias impulsadas en la época. Construir otra realidad es lo que pretende este documento, y plantea que la ley no puede estar por encima de las

3 El resaltado es del editor de la presente edición de ENTORNOS. 
exigencias reales de una sociedad, razón por la que El Manifiesto Liminar rescata el valor de la moral en una sociedad y sin usar violencia alguna la juventud de Córdoba entendió que sus derechos no se negocian, no se piden, se EXIGEN.

Latinoamérica debe reaccionar y dejar la obediencia para tomar el camino de la lucha activa bajo la visión crítica que apoye el progreso. Un gran logro en nuestra sociedad seria que este manifiesto se convirtiera en carta de navegación para nuestras universidades pero para ello se debe retomar el propósito planteado por el Manifiesto, debe ser posible una nueva realidad universitaria que muestre su carácter democrático, libre, impulsora del desarrollo, la investigación, la formación genuina pues el desarrollo de un país está contenido en su educación, por eso es vital invertir y apoyar nuestras universidades y consolidar el docenteinvestigador como un bastión de la resistencia por la democracia en Latinoamérica a partir del dialogo colaborativo entre nuestras naciones.

\section{Referencias bibliográficas}

Banco Mundial (2015) Gasto en Investigación y Desarrollo (\% del PIB). Recuperado de https://datos.bancomundial.org/indicador/ GB.XPD.RSDV.GD.ZS?locations=DE

Diccionario electrónico (2018) Definición de anacrónico. Recuperado de https:// definicion.de/anacronico/
Diccionario electrónico (2018) Definición de Ciencia. Recuperado de http:// conceptodefinicion.de/ciencia/

Manifiesto Liminar (1918) Recuperado de https:// www.unc.edu.ar/sobre-la-unc/manifiestoliminar

Manifiesto Liminar. Disponible: http://www. unc.edu.ar/sobre-la-unc/historia/reforma/ manifiesto

Perozo, S., Arteaga, F. y Fuenmayor, B. (2008). La productividad investigativa de los docentes del Instituto Universitario de Cabimas. Negotium. Recuperado de http:// www.revistanegotium.org.ve/pdf/9/Art4. pdf

Ranking Académico de Universidades del Mundo (2015). Recuperado de http://www. shanghairanking.com/es/ARWU2015.html

Sebastian, J. (2007). Conocimiento, cooperación y desarrollo. Revista Iberoamericana de ciencia tecnología y sociedad. 3 (8). P.p 195-208. Recuperado de http://www. scielo.org.ar/scielo.php?script $=\mathrm{sci}_{-}$ arttext\&pid=S1850-00132007000100015

Telesur (2017) La Revolución de Mayo, el camino de la independencia argentina. Recuperado de https://www.telesurtv.net/news/LaRevolucion-de-Mayo-el-camino-a-laindependencia-argentina-20150521-0061. html 


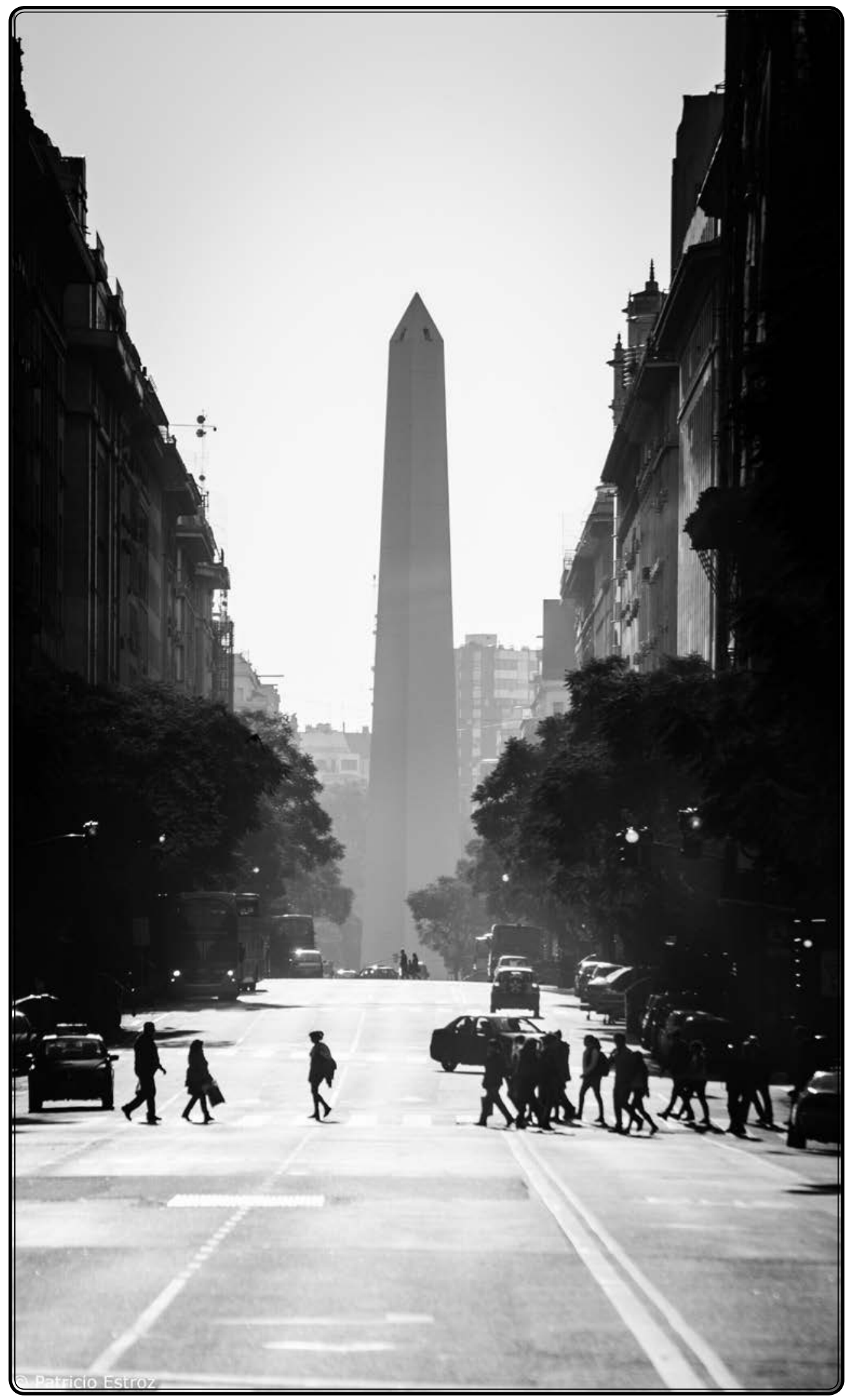

Falo europeo, no dice nada. 